\section{(6) OPEN ACCESS}

\title{
Tobacco smoking and excess mortality in multiple sclerosis: a cohort study
}

\author{
Ali Manouchehrinia, ${ }^{1}$ Mikail Weston, ${ }^{1}$ Christopher R Tench, ${ }^{1}$ John Britton, ${ }^{2}$ \\ Cris S Constantinescu ${ }^{1}$
}

${ }^{1}$ Academic Division of Clinical Neuroscience, University of Nottingham, Queen's Medical Centre, Nottingham, UK ${ }^{2}$ Division of Epidemiology and Public Health, UK Centre for Tobacco Control Studies, University of Nottingham, City Hospital, Nottingham, UK

\section{Correspondence to}

Professor Cris $\mathrm{S}$

Constantinescu, C Floor South Block, School of Medicine, University of Nottingham, Queen's Medical Centre, Nottingham NG7 2UH, UK; cris.constantinescu@ nottingham.ac.uk

Received 5 November 2013 Revised 16 January 2014 Accepted 24 January 2014 Published Online First 25 February 2014

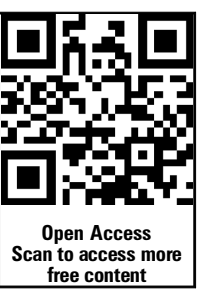

CrossMark

To cite: Manouchehrinia A,
Weston M, Tench CR, et al.
J Neurol Neurosurg
Psychiatry 2014;85:
1091-1095.

\section{ABSTRACT}

Objective As patients with multiple sclerosis (MS) have more than 2.5-fold increased mortality risk, we sought to investigate the impact of tobacco smoking on the risk of premature death and its contribution to the excess mortality in MS patients.

Methods We studied 1032 patients during the period 1994-2013 in a UK-based register. Cox regression model was used to investigate the impact of smoking on the risk of premature death, controlling for confounders. Smoking-specific mortality rates were compared with the UK general population.

Results Of 923 patients with clinically definite MS, 80 (46 males and 34 females) had died by December 2012. HRs for death in current smokers and ex-smokers relative to never smokers were $2.70(95 \% \mathrm{Cl} 1.59$ to 4.58 , $p<0.001)$ and $1.30(95 \% \mathrm{Cl} 0.72$ to $2.32 ; p=0.37)$. The standardised mortality ratio, compared with the UK general population, when stratified by smoking status was $3.83(95 \% \mathrm{Cl} 2.71$ to 5.42$)$ in current smokers, $1.96(95 \% \mathrm{Cl} 1.27$ to 3.0$)$ in ex-smokers and 1.27 ( $95 \% \mathrm{Cl} 0.87$ to 1.86$)$ in non-smokers. Never smokers and ex-smokers with MS had similar mortality rates compared with never smokers and ex-smokers without MS in the male British doctors cohort $(1.12(95 \% \mathrm{Cl}$ 0.63 to 1.97$)$ and $0.54(95 \% \mathrm{Cl} 0.26$ to 1.14$)$, respectively), while current smokers with MS had $84 \%$ higher rate of death compared with current smokers without MS (95\% Cl 1.24 to 2.72).

Conclusions Tobacco smoking can account for some of the excess mortality associated with MS and is a risk determinant for all-cause and MS-related death.

\section{INTRODUCTION}

Multiple sclerosis (MS) is associated with a range of largely irreversible and progressive disability but is not considered a lethal disease. Life span in patients with MS is estimated to be 5-10 years shorter than in the general population. ${ }^{1-3}$ Mortality is a major health outcome, which is often ignored in the studies of neurological conditions such as MS, ${ }^{4}$ possibly due to the long duration of follow-up required. As a result, there is little information about the non-demographic risk factors associated with increased mortality rates. A range of lifestyle, environmental risk factors, demographic characteristics and healthcare interventions influence mortality. Among the lifestyle factors, tobacco smoking is the most prominent preventable cause of premature death, ${ }^{5}$ being associated with a significant decrease in life expectancy, ${ }^{67}$ and has previously been linked to more severe disease in
MS patients. ${ }^{8-11}$ Tobacco smoking is a complex factor in the aetiology and progression of neurological conditions. While tobacco smoking has been shown to reduce the risk of mortality in patients with $\mathrm{PD},{ }^{12}$ its effect on the risk of mortality in MS patients is not clear. Higher prevalence of smoking in MS populations ${ }^{13}$ may explain, in part, the reported shorter life span in individuals with MS compared with the general population.

In this study, we investigated the relationship between tobacco smoking and the life span and mortality rates in a large cohort of MS patients and examined whether smoking can explain the reported increased mortality seen in MS populations.

\section{METHOD}

Settings and study design

We studied participants in the Nottingham University Hospitals MS Clinics database during the period 1994-2013. This is a major regional referral centre for MS in East Midlands Counties of England. Our methods and cohort characteristics have been described in detail elsewhere. ${ }^{11}$ Briefly, the centre covers more than 3000 MS patients. Among all the patients who are regularly seen in these MS specialised clinics, 1032 patients were routinely followed up and details of the disease clinical course, disability scores, date of diagnosis and disease onset, treatment, comorbid conditions, etc., were systematically documented. Our final study population consisted of patients with clinically definite MS according to the McDonald and/or Poser criteria ${ }^{14} 15$ made by an MS specialist neurologist.

\section{Measurements}

Clinical data and smoking history

Smoking history was obtained during patients' first clinic visit at the time of disease onset and/or diagnosis, and patients were grouped as nonsmokers, ex-smokers or current smokers. In the majority of the cases, smoking history was updated and recorded more than once after the disease onset during regular clinic follow-ups. For this study, we used the latest smoking status recorded in the database. The date of the first manifestation of the disease, date of diagnosis, duration of exposure to disease-modifying treatments (DMTs), latest Expanded Disability Status Scale (EDSS) score ${ }^{16}$ recorded in clinic, sex and initial clinical course of the disease (relapsingremitting (RR) vs primary-progressive (PP)) were used in this report. We also calculated the global MS severity score (MSSS), which integrates EDSS 
score and disease duration according to the guidelines published by Roxburgh et al. ${ }^{17}$

\section{Vital status and cause of death}

Vital status of patients was monitored and the exact date of death was obtained through linkage of the MS cohort to National Health Service (NHS) vital statistics as of December 2012 (index date). For the cause of death, both medical records and death certificates were used. Causes of death were categorised into MS-related (death due to MS disability such as bronchopneumonia, pulmonary embolism, sepsis) and non-MS-related deaths (eg, cancers, suicides, cardiovascular diseases). ${ }^{18}$

\section{Statistical analysis}

Patient data from the time of entry into the database until either death or the index date (December 2012), whichever occurred first, were included. Time at risk and death rates were calculated per 1000 person-years. CIs for median survival age could not be estimated as less than half the patients have died by December 2012. Since the distribution was reasonably normal, we used parametric measures and calculated mean survival from birth and after MS onset. Smoking-specific rates were calculated using Cox proportional hazard regression models controlled for sex, onset age, use of DMTs (in a binary group of $\geq 1$ year or $<1$ year) and initial clinical course of MS (RR vs PP). By basing the survival time on age, we made sure that the effects of age as one of the most important factors in progression have been properly controlled for. The final model was checked for proportionality assumption based on the Schoenfeld residuals, and stratification was made if necessary to hold the proportionality assumption. We also calculated standardised mortality ratios (SMRs) and performed external comparison of our mortality to both the UK general population data and mortality rates of male British doctors cohort. ${ }^{19}$ The male British doctors study contains the mortality rates stratified by age and smoking status. The smoking-specific mortality rates from this cohort enabled us to measure the excess mortality in different smoking categories in male patients with MS. SMR was calculated by dividing the observed number of deaths in the cohort by the number of deaths expected from the general population for each sex and age band stratum $(20-24,25-29, \ldots$, up to $>85$ years). Since all the deaths $(\mathrm{n}=80)$ in our cohort occurred in the 2001-2012 calendar period, we used 2006 UK mortality rates as the corresponding reference rates, obtained from the UK Office for National Statistics for each sex and age group. ${ }^{20}$ All statistical analyses were performed with Stata V.11.2. ${ }^{21}$

\section{FINDINGS}

Our cohort consisted of 923 (89\% of 1032 subjects) individuals with clinically definite MS and full data for analysis. In total, $70 \%$ of the subjects were female, $11 \%$ had PP MS at disease onset and 89\% had RR MS at onset. Of those RR MS subjects, $40 \%$ had transited to secondary progressive (SP) MS. In general, deceased patients in our cohort had significantly older onset age, longer disease duration and higher MSSS and EDSS scores compared with survivors. Also, $58 \%$ of the deceased patients and $30 \%$ of survivors were male; $45 \%$ of the survivors had received DMTs for 1 year or longer compared with only $16 \%$ of deceased subjects. Average treatment duration was 4.73 (SD \pm 3.36 ) years for the whole cohort. Despite the decrease in the prevalence of ever-smoking in the UK general population, ${ }^{22}$ there was an increase of approximately $12 \%$ in the proportion of ever smokers in our cohort in 2000-2010 compared with that of the proportion before 1990 (data not shown) in the MS cohort. Table 1 shows the baseline demographic and MS-specific characteristics of our cohort by vital status at our index date.

\section{Length of follow-up and smoking status}

The 923 patients contributed a total of 18717 person-years of data. There were 80 deaths recorded in our cohort, representing a mortality rate of 4.35 (95\% CI 3.43 to 5.34) per 1000 person-years. This rate was higher in males $(8.68,95 \%$ CI 6.52 to 11.56$)$ than in females $(2.47,95 \%$ CI 1.76 to 3.48$)$. When compared with the frequency of $50 \%$ in the whole cohort, $67 \%$ of the deceased subjects were ever smokers $(n=54)$. All nine patients with RR MS who died were ever smokers compared with $44 \%$ of PP MS and almost $68 \%$ of SP MS patients. Of patients with relapse onset MS, $37 \%$ among those who were still alive and $67 \%$ in the deceased group had transited to SP MS.

\section{Survival rates and role of smoking}

Estimated mean survival was 76.8 years (95\% CI 74.6 to 79) for the whole cohort. Estimated mean survival was 81 (95\% CI 78 to 83.6$)$ years in non-smokers, $78.4(95 \%$ CI 75.2 to 81.5$)$ years in ex-smokers and 71.5 (95\% CI 68.8 to 74.2$)$ in current smokers (Log-rank test, $\left.\chi^{2}(2)=20.12, p<0.001\right)$ (figure $\left.1 \mathrm{~A}, \mathrm{~B}\right)$. The estimated mean survival was not different between RR MS and PP MS (Log-rank test, $\chi^{2}(1)=0.38, p=0.53$ ).

While controlling for onset age, DMT and disease initial course and stratifying for sex (to maintain the proportionality assumption), current smokers but not ex-smokers were at higher risk of death, with a HR relative to never smokers of $2.70(95 \%$ CI 1.59 to $4.58 ; \mathrm{p}<0.001)$ and $1.30(95 \%$ CI 0.72 to 2.32 ; $\mathrm{p}=0.37$ ), respectively. Exposure to DMT for 1 year or longer was associated with $50 \%$ (HR $0.50,95 \%$ CI 0.26 to 0.93 ; $\mathrm{p}=0.03)$ reduction in the risk of death, and each year increase in age at the onset of MS was associated with 4\% (95\% CI 0.94 to $0.98 ; p=0.004)$ decrease in the risk of death. Risk of death was not significantly increased in PP MS patients compared with RR MS (HR 1.16, 95\% CI 0.65 to 1.06 ; $\mathrm{p}=0.65$ ).

Since both EDSS and year of birth are significant contributory factors in the risk of death, they were added to the model to check whether the effect size of smoking remains significant.

Table 1 General demographic characteristics of the cohort by vital status at December 2012

\begin{tabular}{lccc}
\hline & $\begin{array}{l}\text { Deceased } \\
(\mathbf{n}=80)\end{array}$ & $\begin{array}{l}\text { Alive } \\
(\mathbf{n}=843)\end{array}$ & $\begin{array}{l}\mathbf{p} \\
\text { Value }\end{array}$ \\
\hline Age (mean (SD)) & $56( \pm 12)$ & $51( \pm 10)$ & $=0.001$ \\
Sex (female \%) & $34(42 \%)$ & $610(72 \%)$ & $<0.001$ \\
$\begin{array}{l}\text { Last recorded EDSS } \\
\text { (median (range)) }\end{array}$ & $7.5(6.5-8.0)$ & $5.5(3.0-6.5)$ & $<0.001$ \\
$\begin{array}{l}\text { MSSS (mean (SD)) } \\
\text { Age at the onset (mean (SD)) }\end{array}$ & $7.9( \pm 2.23)$ & $5.34( \pm 2.59)$ & $<0.001$ \\
$\begin{array}{l}\text { Disease duration (median } \\
\text { (range)) }\end{array}$ & $18(10-26)$ & $32( \pm 9.74)$ & $=0.02$ \\
Type of MS & & $15(9-23)$ & $=0.06$ \\
$\quad$ Relapsing-remitting & $9(11 \%)$ & $445(52 \%)$ & $<0.001$ \\
$\quad \begin{array}{l}\text { Primary-progressive } \\
\quad \text { Secondary-progressive }\end{array}$ & $16(20 \%)$ & $87(10 \%)$ & \\
DMT $\geq 1$ year & $55(69 \%)$ & $311(37 \%)$ & \\
\hline
\end{tabular}

DMT, disease-modifying treatment; EDSS, expanded disability status scale; MSSS, multiple sclerosis severity score. 

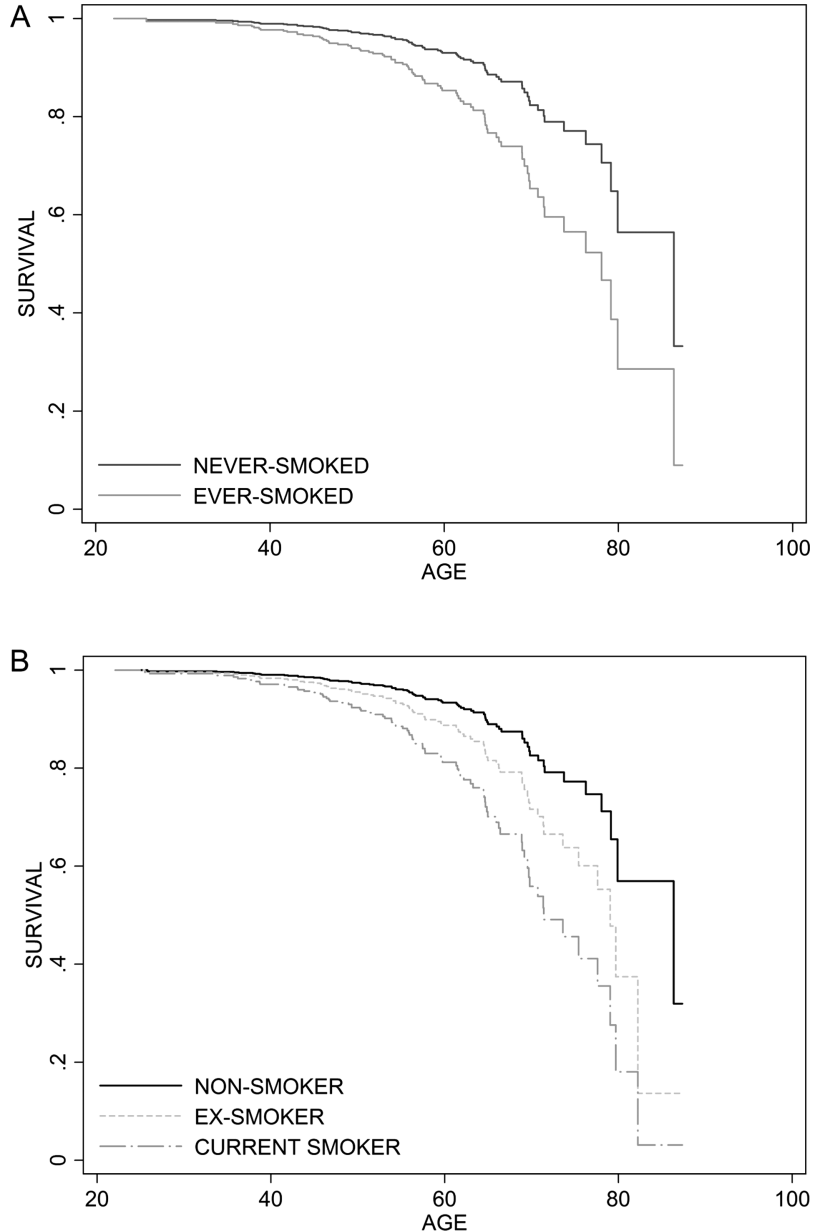

Figure 1 Cox proportional hazard regression graph showing survival from birth (A) by lifelong smoking status and (B) latest smoking status.

When the latest EDSS score and year of birth were added to the model, the effect size of smoking increased to 2.92 (95\% CI 1.50 to $5.71 ; \mathrm{p}=0.002)$ in current smokers and $1.62(95 \% \mathrm{CI}$ 0.79 to $3.34 ; \mathrm{p}=0.18$ ) in ex-smokers compared with nonsmokers and exposure to DMT for at least a year was associated with $68 \%$ reduction in the risk of death (HR 0.32, 95\% CI 0.14 to $0.72 ; \mathrm{p}=0.006)$.

Limiting our survival analysis to those who died from MS-related causes, current smokers were still at higher risk for death, with a HR of 2.93 (95\% CI 1.48 to 5.76 ; p < 0.001$)$ relative to non-smokers. Among ex-smokers, the HR was 1.18 (95\% CI 0.53 to $2.61 ; \mathrm{p}=0.67$ ).

\section{Disability status and cause of death}

Latest recorded disability status was significantly higher in deceased subjects relative to survivors as measured by EDSS score and MSSS. We could not obtain causes of death in two of the decedents. Cause of death was MS-related in $60 \%$ of cases (table 2), with bronchopneumonia accounting for the majority of MS-related deaths. Cancer $(17.5 \%)$ was the commonest non-MS-related cause, and lung cancer the dominant cancer (six deaths). Deaths from cardiovascular diseases (11 cases), suicide (1 case), motor neuron disease (1 case), kidney failure (2 cases), liver cirrhosis and gastrointestinal infarction were also recorded.
Table 2 Summaries of causes of death, onset age, disability score and disease severity by patients' lifelong smoking status

\begin{tabular}{|c|c|c|c|c|c|c|}
\hline \multirow[b]{2}{*}{$\begin{array}{l}\text { Cause of } \\
\text { death }\end{array}$} & \multicolumn{3}{|c|}{ Ever smoked } & \multicolumn{3}{|c|}{ Never smoked } \\
\hline & $\mathbf{n}$ & $\begin{array}{l}\text { Onset } \\
\text { age } \\
\text { (median) }\end{array}$ & $\begin{array}{l}\text { Last EDSS } \\
\text { in clinic } \\
\text { (median) }\end{array}$ & $\mathbf{n}$ & $\begin{array}{l}\text { Onset } \\
\text { age } \\
\text { (median) }\end{array}$ & $\begin{array}{l}\text { Last EDSS } \\
\text { in clinic } \\
\text { (median) }\end{array}$ \\
\hline $\begin{array}{l}\text { MS-related } \\
\text { cause }\end{array}$ & 32 & 36 & 8 & 15 & 33 & 8.5 \\
\hline Pneumonia & 21 & & 8 & 9 & & 8.5 \\
\hline Sepsis & 4 & & 8 & 2 & & 8 \\
\hline $\begin{array}{l}\text { Other or not } \\
\text { specified }\end{array}$ & 7 & & 8 & 4 & & 8 \\
\hline Cancer & 10 & 33 & 6 & 4 & 27 & 7 \\
\hline Cardiovascular & 7 & 38 & 6 & 4 & 36.5 & 7 \\
\hline Other & 2 & 27.5 & 7 & 4 & 38 & 8 \\
\hline
\end{tabular}

\section{Standardised mortality ratio}

All-cause mortality in MS patients was significantly higher than expected in age-matched and sex-matched general population, the SMR being 2.41 (95\% CI 1.95 to 2.96 ; $\mathrm{p}<0.001)$ for males, 1.80 (95\% CI 1.40 to $2.30 ; \mathrm{p}<0.001)$ for females and 1.99 (95\% CI 1.70 to $2.33 ; \mathrm{p}<0.001)$ for both sexes combined. The all-cause SMR in current smokers was 3.83 (95\% CI 2.71 to $5.42 ; \mathrm{p}<0.001)$ and in ex-smokers 1.96 (95\% CI 1.27 to $3.0 ; \mathrm{p}<0.001)$; among never smokers SMR was $1.27(95 \% \mathrm{CI}$ 0.87 to $1.86 ; \mathrm{p}=0.07)$ compared with the rates in the general population.

The non-smokers and ex-smokers with MS did not have significant excess mortality compared with their age-matched and smoking status-matched counterparts in the British doctors cohort study (SMR 1.12, 95\% CI 0.63 to 1.97 and SMR 0.54, 95\% CI 0.26 to 1.14 , respectively). However, the SMR for current smokers with MS compared with current smokers without MS was 1.84 (95\% CI 1.24 to 2.72 ) (table 3).

\section{DISCUSSION}

In this MS population, current smoking was associated with more than 2.5-fold increased risk of death. Current smokers with MS had a reduction of about 10 years in their life expectancy relative to non-smokers with MS. When compared with the general population, increased mortality in this cohort as measured by SMR was seen in current and ex-smokers, but our results indicated that mortality may not be increased in nonsmokers with MS. The risk of death in ex-smokers was considerably lower than that in current smokers. When the mortality in

Table 3 Standardised mortality ratio for all-cause mortality compared with the UK general population and male British doctors cohort

\begin{tabular}{lll}
\hline & SMR (general population) & SMR (male British doctors) \\
\hline Overall & $1.99(1.70$ to 2.33$)$ & - \\
Male & $2.41(1.95$ to 2.96$)$ & - \\
Female & $1.80(1.40$ to 2.30$)$ & - \\
Non-smokers & $1.27(0.87$ to 1.86$)$ & $1.12(0.63$ to 1.97$)$ \\
Ex-smokers & $1.96(1.27$ to 3.0$)$ & $0.54(0.26$ to 1.14$)$ \\
Current smokers & $3.83(2.71$ to 5.42$)$ & $1.84(1.24$ to 2.72$)$ \\
\hline SMR, standardised mortality ratio and Cls $(95 \%)$. &
\end{tabular}


each smoking category in our patients was compared with the mortality in smoking categories in the British doctors cohort study, we found that current smokers with MS have increased mortality risk (84\%) compared with their counterparts without MS. Interestingly, non-smokers and ex-smokers with and without MS had similar mortality rates compared with nonsmokers and ex-smokers without MS. These data are consistent with our recent findings of the negative impact of current smoking on disability and severity of the disease in MS. ${ }^{11}$

The estimated survival age of 77 for our MS population in the present study is comparable to the findings from a recent study in the $\mathrm{UK}^{23}$ and from Canada. ${ }^{3}$ Our patients were two times more likely to die prematurely compared with their agematched and sex-matched counterparts in the UK general population. Although SMRs cannot be comfortably compared due to differences in distribution of the standardisation variables (age and sex) across the study populations, our presented SMR here is lower, though still comparable, with those reported previously. ${ }^{1} 3182425$ The overall reported SMR here compared with the UK general population is higher than the reported SMR of 1.3 in a French study. ${ }^{26}$ Apart from methodological variations, treatment and access to healthcare resources may further explain the lower SMR in the cohort presented here. While 57\% of the patients in the French study and $42 \%$ of our cohort have been exposed to treatment, the majority of the patients in British Columbia $^{3}$ were never exposed to treatment and the follow-up time in the Danish study ${ }^{1}$ predated treatment. This may explain some of the differences seen between our reported SMR here and those reported previously.

In our cohort, the risk of death was halved for patients who had been exposed to at least 1 year of DMTs. However, the assignment of DMTs to a selective population of patients may introduce bias to the results. Our results presented here are in line with the findings from the long-term follow-up of patients participating in the original interferon- $\beta$ clinical trial, which has shown that exposure to treatment may decrease risk of premature death. ${ }^{27}$ Also, follow-up of patients in Taiwan ${ }^{28}$ showed a reduced risk of mortality in patients with history of exposure to DMTs. The mechanism by which DMTs can reduce the risk of premature death is unclear. We could not observe any influence of DMTs in reducing the risk of reaching two EDSS score milestones 4 and 6 in our cohort (data not shown). One possible explanation is the ability of interferon to reduce the risk of infection. ${ }^{29}$ Nevertheless, the potential influence of treatment intervention in MS on mortality deserves further investigation.

Mortality is a major component of population change and many health conditions and interventions reflect on mortality rates. This, along with unique characteristics such as exact date and time, makes mortality a relevant outcome in studies of MS. In the UK, it has been shown that current smokers with MS have 6.7-fold (95\% CI 4.16 to 10.87 ) increased mortality rate compared with the sex-matched and age-matched counterparts without MS while the rate for never smokers was 2.85 (95\% CI 1.86 to 4.37$).{ }^{30}$ Our results confirm a higher mortality rate in current smokers versus non-smokers (HR 2.7, 95\% CI 1.59 to 4.58; $\mathrm{p}<0.001)$.

Our study had some limitations. First, it is possible that our study has missed some of the patients with very severe disease who have died before the data collection. Second, our calculated SMR, which used reference mortality rates from the male British doctors study, were limited to the male patients while $70 \%$ of our cohort were female. In addition, the reported mortality rates in that study of male British doctors, which is a historic cohort (1951-2001), are higher from the more recent ones. Hence, it is likely that the SMR versus male doctors substantially underestimates the excess mortality for the MS cohort for the non-smoker and current smoker groups. We cannot rule out the possibility of reverse causality bias (or the healthy smoker bias ${ }^{31}$ ) when ex-smokers probably quit smoking because of the worsening of their MS. As a consequence, the effect size of current smoking versus ex-smokers may be biased by selection of those current smokers who have experienced fewer disabilities, are still alive and continued to smoke.

To our knowledge, this is the first study investigating smoking as a factor influencing life expectancy in patients with MS. Here we have presented data from a cohort of MS patients in the UK, but the relevance of this study is likely to be worldwide. As shown here, smoking is a significant risk factor for all-cause and MS-related death, causing almost 10 years loss of life expectancy in patients with MS. In contrast, our data suggest that mortality may not be increased substantially in non-smokers with MS relative to the general population and non-smokers in the male British doctors study.

In the general population, tobacco smoking reduces life expectancy mainly by increasing the risk of cancer ${ }^{22}$ and cardiovascular diseases. ${ }^{32}$ In MS, vascular comorbidities were shown to associate with a more severe disease evolution, ${ }^{33}$ which can potentially mediate the effect of smoking on mortality in MS. However, our risk estimates remained almost unchanged when only those who died from MS-related causes were analysed. In addition, we did not observe any increased mortality rate due to cancer and cardiovascular diseases compared with the UK general population (SMR due to cancer $0.61,95 \%$ CI 0.37 to 1.01; and SMR due to cardiovascular diseases $0.83,95 \% \mathrm{CI}$ 0.46 to 1.50 ). The exact mechanism in which smoking increases the risk of premature death in MS deserves further investigation. One possible explanation is the increased risk of mortality due to pneumonia, for which smoking has been shown to be a significant risk factor. ${ }^{34} 35$ In our cohort, the number of ever smokers who died from pneumonia was more than two times higher than never smokers $(n=21$ vs $n=9)$.

On the basis of our findings, there is a strong association between tobacco smoking and premature mortality in patients with MS. The evidence of reduced risk of death among former smokers compared with current smokers calls for effective cessation strategies. Our data suggest that reduction in prevalence of tobacco smoking in people with MS is one factor that can potentially decrease the excess mortality rates seen in MS patients. Tools and information to help smokers with MS stop smoking and non-smokers to never start smoking should be provided to all patients with MS.

Contributors AM was involved in study concept and design, analysis and interpretation of the data and critical revision of the manuscript for important intellectual content. MW was involved in acquisition of data. CRT was involved in analysis and interpretation of results, and critical revision of the manuscript for important intellectual content. JB performed the critical revision of the manuscript for important intellectual content. CSC was involved in developing the study concept and design, and critical revision of the manuscript for important intellectual content. CSC also supervised the study and was also involved in acquisition of data.

Funding The study was supported by University of Nottingham.

Competing interests CSC has received research support, support for travel to scientific meetings, consultancy and speaker honoraria from Biogen Idec, Bayer-Schering, Centocor, GW Pharmaceuticals, Merck-Serono, Morphosys, and Teva Pharmaceuticals.

Ethics approval The study was approved by the National Research Ethics Service East Midlands Ethics Committee Derby-1.

Provenance and peer review Not commissioned; externally peer reviewed.

Open Access This is an Open Access article distributed in accordance with the Creative Commons Attribution Non Commercial (CC BY-NC 3.0) license, which 
permits others to distribute, remix, adapt, build upon this work non-commercially, and license their derivative works on different terms, provided the original work is properly cited and the use is non-commercial. See: http://creativecommons.org/ licenses/by-nc/3.0/

\section{REFERENCES}

1 Bronnum-Hansen $\mathrm{H}$, Koch-Henriksen N, Stenager E. Trends in survival and cause of death in Danish patients with multiple sclerosis. Brain 2004;127(Pt 4):844-50.

2 Sadovnick AD, Ebers GC, Wilson RW, et al. Life expectancy in patients attending multiple sclerosis clinics. Neurology 1992;42:991-4.

3 Kingwell E, van der Kop M, Zhao Y, et al. Relative mortality and survival in multiple sclerosis: findings from British Columbia, Canada. J Neurol Neurosurg Psychiatry 2012:83:61-6.

4 Scalfari A, Knappertz V, Cutter G, et al. Mortality in patients with multiple sclerosis. Neurology 2013;81:184-92.

5 WHO. WHO report on the global tobacco epidemic: warning about the dangers of tobacco. 2011.

6 Sakata R, McGale P, Grant EJ, et al. Impact of smoking on mortality and life expectancy in Japanese smokers: a prospective cohort study. BMJ 2012;345:e7093.

7 Huxley RR, Woodward M. Full hazards of smoking and benefits of stopping for women. Lancet 2013;381:96-8.

8 Hernan MA, Jick SS, Logroscino G, et al. Cigarette smoking and the progression of multiple sclerosis. Brain 2005;128(Pt 6):1461-5.

9 Sundstrom P, Nystrom L. Smoking worsens the prognosis in multiple sclerosis. Mult Scler 2008;14:1031-5.

10 Healy BC, Ali EN, Guttmann CR, et al. Smoking and disease progression in multiple sclerosis. Arch Neurol 2009;66:858-64.

11 Manouchehrinia A, Tench CR, Maxted J, et al. Tobacco smoking and disability progression in multiple sclerosis: United Kingdom cohort study. Brain 2013;136(Pt 7):2298-304.

12 Elbaz A, Bower JH, Peterson BJ, et al. Survival study of Parkinson disease in Olmsted County, Minnesota. Arch Neurol 2003;60:91-6.

13 Nortvedt MW, Riise T, Maeland JG. Multiple sclerosis and lifestyle factors: the Hordaland Health Study. Neuro/ Sci 2005;26:334-9.

14 Poser CM, Paty DW, Scheinberg L, et al. New diagnostic criteria for multiple sclerosis: guidelines for research protocols. Ann Neurol 1983;13:227-31.

15 McDonald WI, Compston A, Edan G, et al. Recommended diagnostic criteria for multiple sclerosis: guidelines from the International Panel on the diagnosis of multiple sclerosis. Ann Neurol 2001;50:121-7.

16 Kurtzke JF. Rating neurologic impairment in multiple sclerosis: an expanded disability status scale (EDSS). Neurology 1983;33:1444-52.

17 Roxburgh RH, Seaman SR, Masterman T, et al. Multiple Sclerosis Severity Score: using disability and disease duration to rate disease severity. Neurology 2005:64:1144-51.
18 Hirst C, Swingler R, Compston DA, et al. Survival and cause of death in multiple sclerosis: a prospective population-based study. J Neurol Neurosurg Psychiatry 2008:79:1016-21.

19 Doll R, Peto R, Boreham J, et al. Mortality in relation to smoking: 50 years' observations on male British doctors. BMJ 2004;328:1519.

20 Office for National Statistics. 2012. http://www.statistics.gov.uk/hub/population/ deaths/mortality-rates.

21 StataCorp. Stata Statistical Software: Release 11. College Station, TX: StataCorp LP, 2009.

22 Peto R, Darby S, Deo $\mathrm{H}$, et al. Smoking, smoking cessation, and lung cancer in the UK since 1950: combination of national statistics with two case-control studies. BMJ 2000;321:323-9.

23 Mackenzie IS, Morant SV, Bloomfield GA, et al. Incidence and prevalence of multiple sclerosis in the UK 1990-2010: a descriptive study in the General Practice Research Database. J Neurol Neurosurg Psychiatry 2014;85:76-84.

24 Sumelahti ML, Tienari PJ, Wikstrom J, et al. Survival of multiple sclerosis in Finland between 1964 and 1993. Mult Scler 2002;8:350-5.

25 Smestad C, Sandvik L, Celius EG. Excess mortality and cause of death in a cohort of Norwegian multiple sclerosis patients. Mult Scler 2009;15:1263-70.

26 Leray E, Morrissey SP, Yaouanq J, et al. Long-term survival of patients with multiple sclerosis in West France. Mult Scler 2007:13:865-74.

27 Goodin DS, Reder AT, Ebers GC, et al. Survival in MS: a randomized cohort study 21 years after the start of the pivotal IFNbeta-1b trial. Neurology 2012;78:1315-22.

28 Tsai CP, Lee CT. Impact of disease-modifying therapies on the survival of patients with multiple sclerosis in Taiwan, 1997-2008. Clin Drug Investig 2013;33:647-52.

29 Rothman KJ, Greenland S, Lash TL. Modern epidemiology. 3rd edn. Philadelphia, PA: London: Lippincott Williams \& Wilkins, 2008

30 Lalmohamed A, Bazelier MT, Van Staa TP, et al. Causes of death in patients with multiple sclerosis and matched referent subjects: a population-based cohort study. Eur J Neuro/2012;19:1007-14.

31 Becklake MR, Lalloo U. The 'healthy smoker': a phenomenon of health selection? Respiration 1990:57:137-44.

32 Pope CA III, Burnett RT, Turner MC, et al. Lung cancer and cardiovascular disease mortality associated with ambient air pollution and cigarette smoke: shape of the exposure-response relationships. Environ Health Perspect 2011;119:1616-21.

33 Marrie RA, Rudick R, Horwitz R, et al. Vascular comorbidity is associated with more rapid disability progression in multiple sclerosis. Neurology 2010;74:1041-7.

34 Lange $\mathrm{P}$, Vestbo J, Nyboe J. Risk factors for death and hospitalization from pneumonia. A prospective study of a general population. Eur Respir $J$ 1995;8:1694-8

35 LaCroix AZ, Lipson S, Miles TP, et al. Prospective study of pneumonia hospitalizations and mortality of U.S. older people: the role of chronic conditions, health behaviors, and nutritional status. Public Health Rep 1989:104:350-60. 